\title{
LA FRONTERA SUR: LA ARQUEOLOGÍA Ychma vista Desde el Valle de Mala
}

Henry Tantaleán *

\section{Resumen}

En este artículo se presenta una serie de planteamientos jerarquizados que esperan ayudar a definir y/o delimitar concreta y conceptualmente los limites reales, metodológicos y epistemológicos de la sociedad conocida en la literatura arqueológica como Ychma, la misma que se estableció específicamente en los valles del Rímac y del Lurín en la costa central durante el período prehispánico denominado como Intermedio Tardío (circa 900 DNE-1470 DNE) y que sobrevivió en varios aspectos socio económicos y sociopolíticos a la ocupación Inca de este área.

Para realizar dichos planteamientos nos basamos en nuestro conocimiento de la materialidad social adscrita a lo Ychma y, sobre todo, en su negación dialéctica en la parte sur de la costa central reconocida por nosotros en el área del valle del rio Mala, donde llevamos casi una década de trabajo de campo y de comprensión de los fenómenos sociales intra e intervalles.

\section{Palabras clave}

Ontología, epistemología, metodología, categoría, frontera.

\begin{abstract}
In this paper we show a serial of jerarchized approachs that we expect help to define and to delimit concret and conceptually the real, methodological and epistemological borders of the society knowed in the archaeological literature as Ychma, which one was settled specificly in the Lurin and Rimac valleys at the central peruvian coast during the prehispanic period called Late Intermediate (circa 900 DNE1470 DNE) but survived in many socioeconomic and sociopolitical aspects to the Inca occupation of the area.

To carry out such approachs we have based in our knowledge of the social materiality described as Ychma y, above all, in it dialectical negation in the south part of the central coast recognized for us in the area of the Mala river valley, where we have almost a decade of fieldwork and understanding of the social phenomenae both intra and inter valley.
\end{abstract}

\section{Keywords}

Onthology, epistemology, methodology, category, border.

* Departamento de Prehistoria, Universidad Autónoma de Barcelona, España. Correo electrónico: henrytantalean@yahoo.es 
"Sobre esas aguas fangosas puedes ver lo que ha de venir, sí es que no te lo ocultan los vapores del pantano"

Los poetas bordean la laguna Estigia.

La Divina Comedia. Dante Alighieri.

\section{INTRODUCCIÓN}

En este texto se tratan algunos temas que creemos relevantes para comenzar a entender el contenido real de las sociedades de la costa centro sur y, en este caso, a esa que denominamos Ychma. En ese sentido, creemos relevante, en tanto arqueólogos, definir sus características socio-económicas y sociopolíticas internas y delimitar los fenómenos sociales con relación a otros. Por ello, creemos que solamente mediante la propia materialidad social en estudio, en tanto consecuencia, de la producción social en una situación históricamente constituida, podremos superar nuestras analogías etnográficas, etnohistóricas y nuestros lugares comunes que se han tornado en nuestras metodologías directas para entender la realidad social y comenzar a llenar de contenido real a nuestras sociedades en estudio. Esto se hace necesario desde que se observa que nuestro proceder en la representación de las sociedades prehistóricas se basaría, por lo general, en la construcción de entes, y que podemos "bautizar" con nombres tan disímiles como "cultura", "jefatura", "curacazgo", "señorío", "nación”, "confederación”, "provincia", "polity", etc.

Por ello, para entender en primera instancia como hemos llegado a darle nombre a las cosas, tendríamos que hacer una reflexión, aunque sea sintética, de nuestras formas de aprehender esta realidad social.

\section{LA CONSTRUCCIÓN HISTÓRICA DE LO YCHMA}

El viejo debate acerca de cómo denominar a las sociedades que hemos "descubierto"1@ s arqueólog@s es un problema ontológico y epistemológico que creemos que se tiene que comenzar a discutir. En primer lugar, creemos que es un problema ontológico, porque tiene que ver con la forma como concebimos (pensamos la cosa, la idealizamos) el objeto de conocimiento ("etnia", "sociedad", "cultura", "formación socio-económica", etc), es decir cuestiones relacionadas con la pregunta ique es la realidad con la que trabajamos?

En segundo lugar, es un problema epistemológico porque existe implícita o explícitamente una forma de reconocer en la realidad a dichas construcciones históricas. Se podría admitir sin temor, que la mayor parte procede de una ontología idealista (la realidad es dependiente de nuestra percepción). En ese sentido, la mayoría de la "explicaciones" acerca del fenómeno Ychma son de corte idealista porque como lógica se asume que nosotros conocemos la realidad social pasada mediante una serie de enunciados y prejuicios presentes aplicados directamente a nuestro producto ${ }^{1}$. De hecho, el acto de darle nombre a algo supondría el conocimiento de aquello y muchas veces nuestra práctica se ha orientado a esto.

Epistemológicamente, se resuelve de la misma manera, pues, el principio establecido o "respetado"2 es lo que conduce nuestras inves-

1 Entendido como esto mismo, un producto realizado por nosotr@s y no re-producción de lo pasado. Asimismo, dentro de la lógica capitalista este producto es algo que queremos o debemos ofrecer a un consumidor.

2 Las autoridades académicas imponen ciertas ideas o planteamientos y adentro de las luchas internas o los partidismos aquellos se terminan reproduciendo sin someterlos a crítica. 
tigaciones, una cuestión que se hace patente, por ejemplo, en la utilización bastante libre del método hipotético-deductivo. Por ello, generalmente llegamos a interpretar a la sociedad Ychma u otras, por analogía con otras sociedades más cercanas (temporal y espacialmente) o simplemente mediante un "razonamiento lógico" o sentido común en el que la apariencia (forma) supone una identidad (esencia). Quizá, finalmente no signifique más que un ejercicio hermenéutico o interpretativo donde cada quien subjetiviza a los objetos y a sus productor@s y los coloca dentro de categorías más o menos entendidas por el ambiente académico y que debemos ser conscientes que de esta misma forma se reproduce en la educación normal.

Así pues, epistemológicamente, se ha desarrollado alguna homologación entre lo Ychma como un "señorio", "jefatura" o "cacicazgo". Independientemente, de la formación académica o vivencial de cada proponente de dichas categorías sociopolíticas (sí es que estas realmente se han entendido y planteado como tales) existe una cuestión muy importante en la forma de concebir a lo llamado como Ychma y eso debería suponer entenderlo internamente como algo compuesto por grupos sociales con intereses diversos y hasta confrontados (pre-estatal o estatal) o, por lo menos, cualquier forma de entender como se mueve en su conjunto esta sociedad en su devenir. De hecho, ni siquiera desde una perspectiva procesualista se le concibe como una "sociedad compleja" o "jefatura compleja" (Earle 1978, Johnson y Earle 2003. Ver críticas recientes en Yofee 2005), algo que, pese a sus connotaciones evolucionistas sociales, podría resultar positivo para un debate que contraste la teoría con la práctica. Sin embargo, independientemente de las "etiquetas" que se le concedan a dichas sociedades, la teoría general que subyace en muchas de las formas de observar a dichas sociedades es evolucionista y más allá de la falta de investigaciones que, casi siempre se ponen como excusas de lo poco que conocemos sobre ellos, lo que prima es la inexistencia del reconocimiento de la sociedad como algo contradictorio socialmente hablando o, si queremos, como plantean Elizabeth Brumfiel y John Fox (1994) como "facciones en competencia".

En ese sentido, se puede apreciar mediante la literatura disponible que lo Ychma correspondería a un punto de vista de la sociedad como un organismo conservador. De hecho, a pesar que la antropología económica sustantivista de Karl Polanyi (1957) expresaba mediante sus categorías de reciprocidad y redistribución el reconocimiento de organizaciones sociales desde una perspectiva no europea, se ha terminado idealizando a las sociedades de jefatura como sociedades igualitarias y sin conflictos y, en algunos casos en los que existiría un "pacto social" (Villacorta 2003:156), interesante forma de aglutinación social si se mira desde la historia de la filosofía política donde este planteamiento tendría espacio como una interesante aplicación al mundo andino de las tesis "iusnaturalistas" o del contrato social, por ejemplo, de Jacques Rousseau o Thomas Hobbes (Bobbio 1987). En ese sentido, nuevamente el idealismo se expresa mediante los materiales para otorgarle cuerpo a algo que quizá suponga un proceso histórico que deberíamos ser más honest@s en representar.

De esta manera, se puede ver que a pesar de que existen claras indicaciones que existieron diferencias en el tratamiento funerario de los individuos en un mismo cementerio asociado con lo Ychma (Díaz y Vallejo 2002, Díaz 2004), no se plantea una diferencia socio-económica en la vida real de los individuos de esta sociedad. Claro está, sin fechados radiocarbónicos seguros nunca podremos conocer la horizontalidad temporal de dichas prácticas funerarias. Menos aun, sin conocer la procedencia real de tantos muertos como podría ser el caso del publicitado cementerio del área arqueológica de Puruchu- 
co-Huaquerones que incorpora en las tumbas objetos de diferentes tradiciones cerámicas (Cock 2005).

Sin embargo, antes de ingresar a la cuestión metodológica empleada para reconocer que es Ychma y que no lo es, habría que precisar una suerte de genealogía foucaultiana acerca de cómo hemos terminado dándole nombre a esta sociedad. Esto requiere un poco de esfuerzo de síntesis y de esquematización del proceso multilateral de su producción, pues, este ha sido el lugar de encuentro de la etnohistoria, arqueología, antropología, sociología, etc. Para ser precisos, como hemos apuntado arriba, todo ha girado en el nombre de la cosa como si de resultas de la palabra (el verbo), la misma evocase automáticamente una realidad concreta temporal y espacial. De esta manera, lo Ychma se ha constituido en una esencia trans-histórica que no se conoce específicamente más que mediante la "cerámica diagnostica" (Bazan 1990, Vallejo 2004, Feltham y Eeckhout 2004) y la arquitectura monumental como los denominados "Palacios" o Pirámides con Rampa (PCR) (Paredes y Franco 1987, Shimada 1991: XXXIX, Eeckhout 2003, Farfán 2004). ${ }^{3}$ Aquí solo cabe destacar los principales protagonistas de la gestación de lo Ychma. Dejando de lado a los primeros cronistas del siglo XVI (Pizarro 1968[1533], Estete 1947[1534], también ver recopilación en Ravines 1996) que, con sus prejuicios económicos, políticos y morales europeos y retomando las versiones de sus informantes interesados en su "verdad" (D'Altroy 2003:20, Eeckhout 2003:176) nos presentan información que debemos ser cautos en aceptar, nos concentraremos en la arqueologia relacionada a lo Ychma realizada en el siglo pasado.

De esta forma, la construcción moderna (en todo ese sentido) de lo Ychma comenzó con ese "Huancho" de Francisco Iriarte (1960, reeditado por el Boletín de Lima en 2000) y que, originalmente, fue planteado por Carlos Romero en 1924 como un grupo "aymara" invasor de la costa central y que, también, fue utilizado por Pedro Villar Córdova (1935) y Louis Stummer (1954, en Silva y Jaime 2005:32) con las mismas implicancias étnicas e invasoras. A este nombre, se le superpuso el "Ichma" de Francisco Bazán del Campo $(1990,1992)$ que, originalmente, había sido planteado por Maria Rostworowski (1972), desde la etnohistoria, en la década de 1970. Finalmente, ahora a este mismo fenómeno social se le ha etiquetado como "Ychsma" en la reciente compilación realizada por Peter Eeckhout (2004).

Sin embargo, lo cierto es que todo este conocimiento de lo Ychma se restringe a seriaciones cerámicas y a excavaciones en lugares que suponen ocupaciones múltiples como cementerios o espacios públicos reocupados (por ejemplo, Armatambo, Huaquerones). Pese a ello, se asumen muchas fases o tipologías y se corren como un telón teórico sobre el teatro de la vida prehispánica, incluso sin haber visto la obra completa.

\footnotetext{
3 Adicionalmente, se ha planteado dos modelos que se han contrapuesto para explicar la existencia de estos edificios en el mismo sitio de Pachacamac: el "modelo de Embajadas" y el "modelo Dinástico". El primero es un modelo desarrollado desde las épocas de Arturo Jiménez Borja, inspirado en las referencias etnohistóricas y algún trabajo de campo limitado. El segundo modelo se ha planteado recientemente (Eeckhout 2003, 2004), inspirado en excavaciones más sistemáticas y siguiendo el modelo de los palacios secuenciales construidos por cada gobernante de la ciudadela Chimú de Chan Chan (Moseley 1975). Más allá de esta controversia y como los mismo fechados de Eeckhout lo hacen tangible (Michczynski et al. 2003) la evidencia de la secuencialidad constructiva de dichos edificios es bastante endeble y, en el caso de serlos, se aprecia que los mismos estarían ubicados cronológicamente en los momentos previos y hasta contemporáneos de la ocupación Inca del sitio de acuerdo con las fechas que son ampliamente aceptadas para su llegada a la costa central.
} 
Sin embargo, más allá de esta cuestión etiquetadora y que reconoce el último autor en su última síntesis sobre el tema (Eeckhout 2004:417), dicho nombre lleva implícito un “apellido" y que le extiende carta de naturaleza a su lugar en el mundo de las cosas pasadas. Aquí nos referimos al tema de las categorías o conceptos que preceden a lo Ychma o subyacen en este nombre cuando se lo invoca. Claramente, aquí nos enfrentamos al tema de las categorías sociopolíticas. Así, tenemos las categorías más populares de "Señorío" y "Curacazgo", ambas usadas en algunos casos sin saber el porqué pero que, según se desprende de su caracterización, se encontrarían íntimamente relacionadas con el concepto de "Jefatura". Independientemente de la realidad de la existencia de esta categoría procedente del procesualismo clásico, por ejemplo de Elman Service (1975), la cuestión importante gira en torno al verdadero funcionamiento en términos económicos y políticos de este tipo de sociedad. Esta cuestión se entiende cuando conocemos cuales son los elementos significativos dentro de la forma de concebir a una Jefatura. Para no extendernos en el mismo debate que ya hemos tocado en otro lugar (Tantaleán 2005:92), solo una critica aquí con relación a esta caracterización de lo Ychma: iconocemos realmente si adentro de lo denominado como Ychma existieron asimetrías socio-económicas y socio-políticas?, es decir, irealmente la reciprocidad y la redistribución fueron las características principales de esta sociedad?.

Otros nombres, como "etnia" (Rostworowski 1972) o "nación” (Cornejo 1999, 2000, 2002), obviamente, proceden del mundo de la identidad social. En el primer caso, la "etnia" se puede asociar con la existencia de una especie de unidad lingüística y de comunidad biológica y, en el segundo término, nos encontramos con ese fenómeno político que reuniría a muchos individuos en una sola "cultura" en un territorio político concreto (Hobsbawn 1992). De entrada, reconocer esto simplemente mediante la materialidad social supone desconocer la forma de producción más extendida en una sociedad y fijarse en los objetos más "diagnósticos" o de una suerte de estética del momento como proyección de esa comunidad concreta. Asimismo, el tema de la existencia de una "nación Ychma" supondría reconocer, por lo menos, su forma de organización sociopolítica enmarcada en un territorio con limites reales, no necesariamente fijos, pero sí de un control espacial de recursos humanos y naturales. Incluso, en el caso ser una sociedad sin clases o igualitaria, se esperaría una autoidentificación con algo concreto (por ejemplo, un territorio) y a partir de allí como negación de otras sociedades vecinas o "diferentes". Así pues, creemos que el tema de las fronteras elusivas (Tantaleán en prensa, también ver Vogel 2003) que ya manifestábamos en el V Simposio de Arqueología organizado por estudiantes de la Universidad Villarreal es importante para comenzar a entender este tópico tan importante.

Para sintetizar, es probable y, esperamos equivocarnos, que en la actualidad poseemos una gran capacidad para dar nombres a las cosas pero no para devolverles la vida social que las originaron. Solo recogiendo esas "migas de pan" que nos han dejado esas sociedades en ese bosque tan oscuro llamado pasado, podremos darconell@s.

Por todo lo anteriormente mencionado, lo que se hace evidente es que todo este conocimiento de lo Ychma a nivel metodológico, se restringe a seriaciones cerámicas, análisis de los planos arquitectónicos y a algunas excavaciones en lugares que suponen ocupaciones múltiples como cementerios o espacios "públicos"4 reocupados o "huacas".

4 Por lo general, se asume que los espacios abiertos como plazas o edificios con amplias superficies son públicos cuando realmente estos podrían pertenecer a los sujetos que los administran. De esta forma, se homologa uso con propiedad. 


\section{Metodologia utilizada para definiR lo YCHMA}

La metodología operativa, pues, claramente como hemos visto arriba estará condicionada por la ontología y epistemología descrita. De hecho, a comienzos del siglo XXI se sigue trabajando en contextos arqueológicos que no despejan las dudas al respecto de como se produjeron las sociedades de los valles más cercanos a la capital del Estado peruano. La tipología cerámica vendría a ser la "punta de lanza" metodológica desde los años 50 para adelante y que se superpuso a la época precedente donde los datos y/o narraciones etnohistóricas implicaban un difusionismo o migracionismo (serranos versus costeños) como forma de explicar la existencia de los "Huanchos" en los valles del Rímac y Lurín.

Así, mediante la cerámica tendremos conspicuos estudios tipológicos cerámicos que han aportando secuencias cada vez mas ajustadas (Díaz y Vallejo 2002, Feltham y Eeckhout 2004, Vallejo 2004). Sin embargo, todas ellas han sido construidas mediante vasijas cerámicas de colecciones, enterramientos o de espacios públicos multicomponentes. De esta manera, el consumo individual se confunde con la producción social.

Una alternativa que ha traído esperanzas para conocer a lo Ychma, lo plantea el análisis de la arquitectura (Eeckhout 2003, Villacorta 2003, 2004 y ver aportes interpretativos en el área andina de Moore 1996, 2005). Sin embargo, poco se sabe acerca de la arquitectura Ychma nativa y casi siempre se confunde con lo Inca oficial o durante su ocupación. De hecho, no existen estudios sistemáticos importantes sobre otros tipos de asentamientos Ychma pre-incas en el valle del Lurín ${ }^{5}$. Si alguien construyó los grandes edificios o "palacios" Ychma seguramente no fueron los que los terminaron habitando. Aquí el sendero de los caminos que se bifurcan, estaría plasmado en la pregunta: ¿existieron los sitios domésticos o han desaparecido? Quizá, el acelerado urbanismo de la ciudad capital halla dado cuenta de esos asentamientos (aunque contrastar con el catastro de Milla de 1974) que podrían ser recuperados mediante prospecciones intensivas. Sin embargo, una cosa que no debemos olvidar es que nada es en sí mismo y si queremos pensar en "palacios" también tendríamos que pensar en los "no-palacios" o aldeas.

\section{Una alternativa PARA DEFINIR A LAS SOCIE- DADES DEL VALLE DEL RÍMAC Y LURIN DEL INTER- MEDIO TARDIO}

Para finalizar esta primera sección del artículo, supongo que 1@s lector@s esperarán una propuesta para el "nombre de la cosa" en cuestión. Sin embargo, nuestra propuesta no puede ser nuevamente ideal, tendrá que partir de la materia misma, de nuestro objeto de estudio, por algo somos arqueólog@s y tenemos un compromiso con esos materiales que algun@s llaman patrimonio. La propuesta no puede ser nuevamente un nombre ni muchos menos un "significado", un "simbolismo" o una "percepción" relacionada con los artefactos (incluida aquí la arquitectura), como esperarían algunas posturas arqueológicas postmodernas (Hodder 1988, Tilley 1994, 2004, Thomas 1996, Gil García 2001, 2002, Hernando 2002).

Las cosas no existen por sus nombres y solo son reales por y en su contenido. La realidad social tiene un contenido perdido en el tiempo pero remanente en sus fragmentos dejados por sus productor@s. El estudio de las categorías y nuevas propuestas de modelos de interpretación, interesa como historiografía y, de hecho, es en lo que hemos recalado en esta primera parte del texto. Sin embargo, el objetivo de la reflexión no puede ser otra reflexión ni, mucho

5 Aunque en el valle de Lurín se conoce una serie de asentamientos domésticos (Negro 1977, Bonavia 1965, Bueno 1982, Feltham 1983, Marcone 2004, Eeckhout 1997, Sánchez 2000). 
menos, la contemplación. Tiene que ser nuestra praxis, esa práctica que hasta Ian Hodder $(1995,2000)$ planteaba como compromiso con el pasado. Sin embargo, nuestra praxis tiene que solventar las contradicciones entre lo que pensamos y lo que es (o ha sido) y esa contradicción no puede, por nuestro propio objeto de estudio, ser resuelta en las ideas, categorías o discursos. Esta contradicción tendrá que ser resuelta mediante la materia y ser ella misma la garantía de objetividad y que esperamos que nos ubique en el mundo y les retorne a nuestros materiales arqueológicos, por insignificantes que parezcan, su verdadero lugar en el pasado: su pasado.

En este sentido, déjennos presentarles algunas cosas procedentes del valle de Mala, área en la cual investigamos desde algún tiempo y nos esforzamos por entender desde su propia historia. Confrontando estos datos con los que aparecen en este volumen esperamos obtener una imagen más clara de la frontera socioeconómica y sociopolítica de lo conocido como Ychma.

\section{INVESTIGACIONES EN EL VA-} LLE DE MALA Y SU RELACIÓN CON LO YCHMA

El Valle de Mala ha sido concebido en algunas representaciones arqueológicas como parte perteneciente o de influencia de lo conocido como Ychma (Bueno 1982, Eeckhout 1997, 1999, Vallejo 2004). Nuestra investigación antes de asumir dichos supuestos tiene como objetivo entender la realidad social prehispánica de este valle y desde allí, entender las relaciones que pudieron haberse dado con lo Ychma y otras sociedades menos comprendidas. Como sabemos, algunos investigadores que han trabajado en esta zona o han tocado este territorio de manera tangencial le han imprimido una "persona- lidad" a este valle (Villar Córdova 1935, Bonavia 1958, Tello 1959, Williams y Merino 1976, Engel 1966, 1984, 1987). Toda esta cuestión aquí resaltada no hace más que recordar como esta "construcción" de la historia del valle ha devenido en la aceptación de ciertos lugares comunes en el pensamiento arqueológico de la costa central y, a pesar que, su objetivo sería el de llenar el vacío arqueológico de la costa centro sur, por el contrario, ha resultado potenciando el desconocimiento concreto de la materialidad social de este valle.

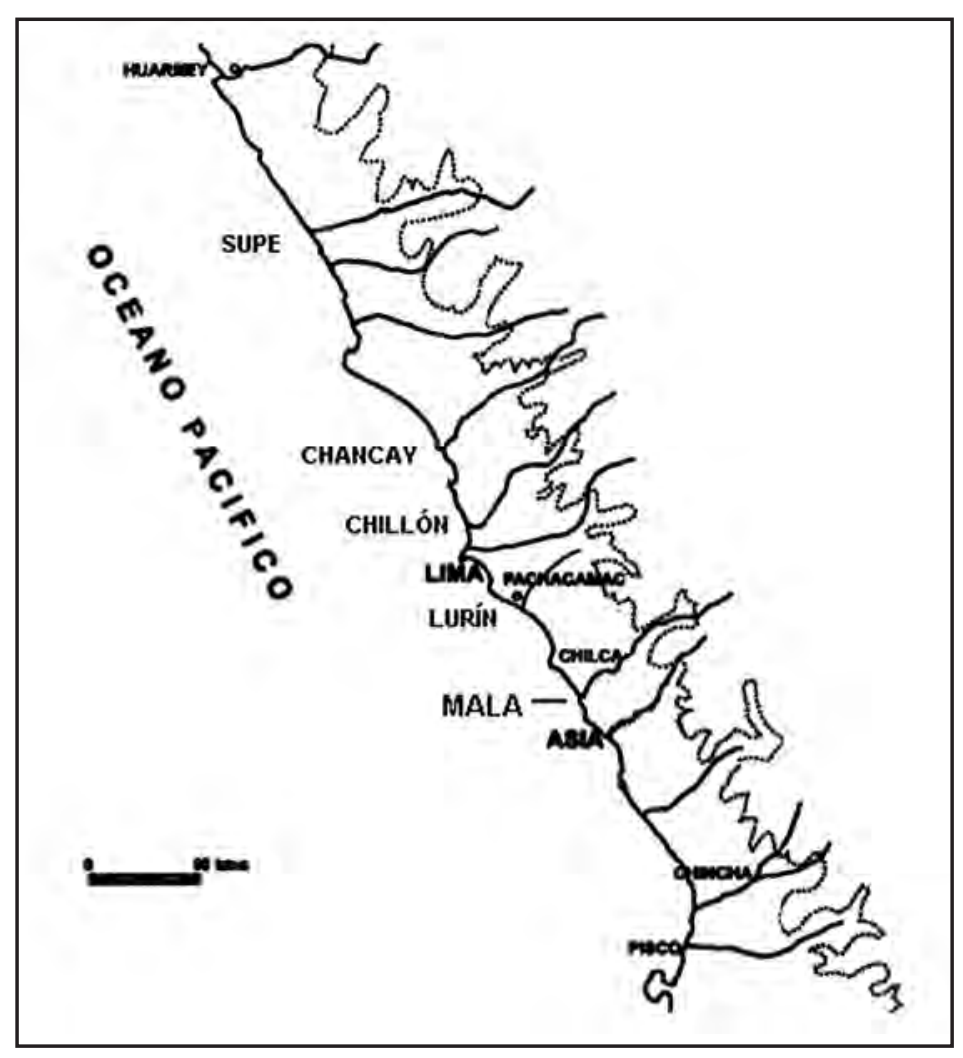

Figura 1. Ubicación del valle de mala en la costa central. 
5.1. Nuestra metodología de investigación en el valle de Mala

Desde el inicio de nuestra investigación en el valle de Mala hemos apostado por el reconocimiento regional. Iniciándose como un proyecto inspirado en el análisis de patrones de asentamiento (Tantaleán 1996) y retomando el catastro de Williams y Merino (1976), en el presente estamos desarrollando una metodología más coherente con los propios materiales de la zona, su localización en el espacio y su explicación como espacios de producción de vida social, tanto local como inter-regionalmente (Tantaleán y Pinedo 2007) (Fig. 2). De hecho, en los

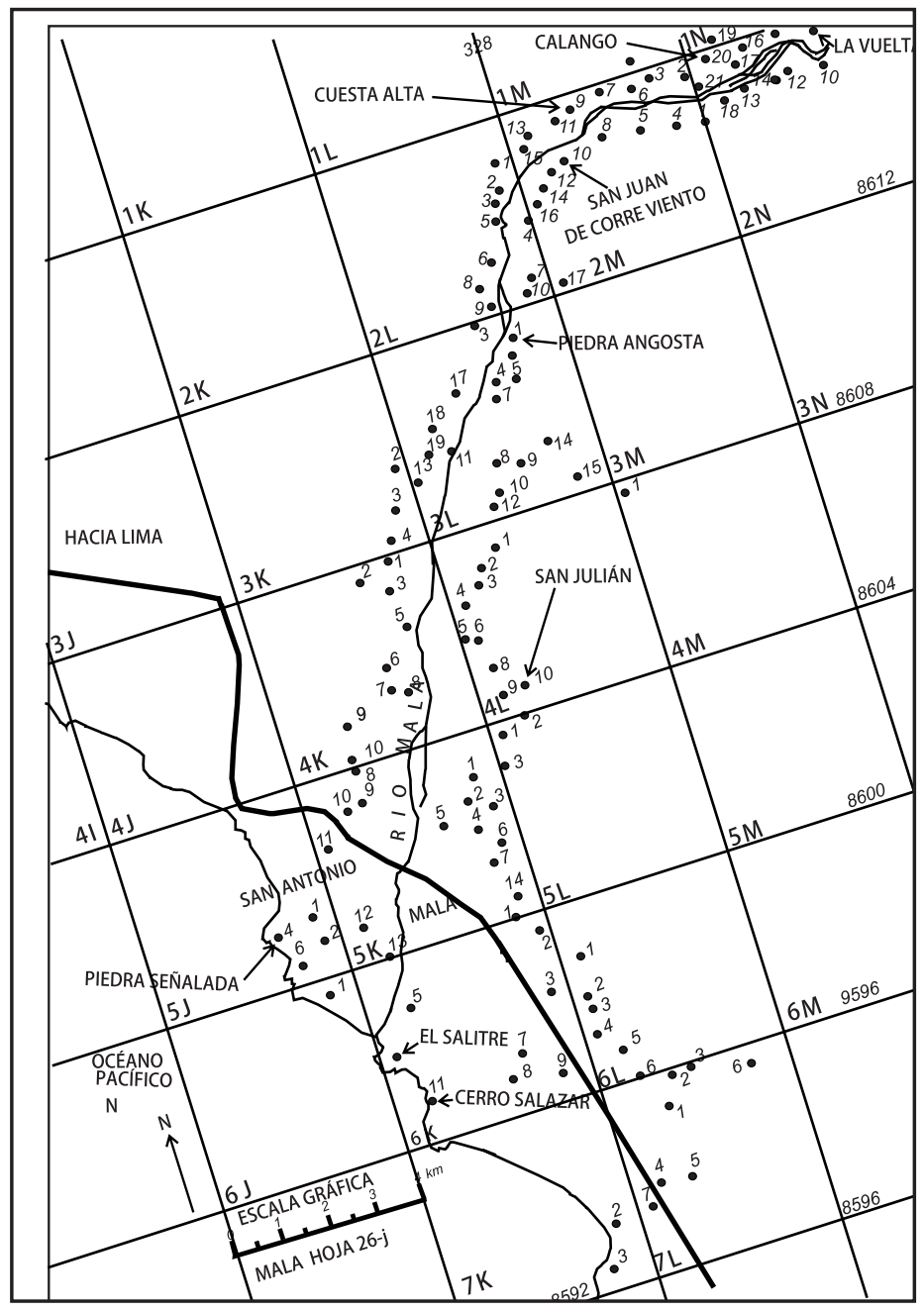

Figura 2. Mapa con los sitios arqueologicos del valle de mala basado en Williams y Merino y nuestras observaciones en el campo. últimos años estamos apostando por un análisis espacial del valle mediante las vistas satélitales y prospección superficial que nos ayudarán a cuantificar la cantidad y la procedencia del trabajo social acumulado en cada asentamiento o lugar social. El análisis de la cerámica también es un elemento importante en nuestra investigación y desde el comienzo nuestro objetivo ha sido definir la extensión de la dispersión (producción y consumo) de la cerámica allí producida y consumida. De hecho, para aclarar el panorama de la materialidad social que aparece en el valle, estamos re-analizando la cerámica del sitio de Puerto Viejo en Chilca depositada en el Museo de Arqueología de la UNMSM y que Duccio Bonavia utilizó para definir dicho estilo (Bonavia 1958) y al que tantas veces se hace referencia y se asume o confunde como Ychma (aunque ver Makowski y Vega-Centeno 2004).

\subsection{Las sociedades loca-} les del Intermedio Tardío del valle de Mala

En un primer acercamiento a esta cuestión planteamos la presencia de dos grupos sociales para el valle bajo y medio del rio Mala. Uno de ellas estaría asociado a algunas formas arquitectónicas y cerámicas de la sierra y a las del litoral. Obviamente, esta división 


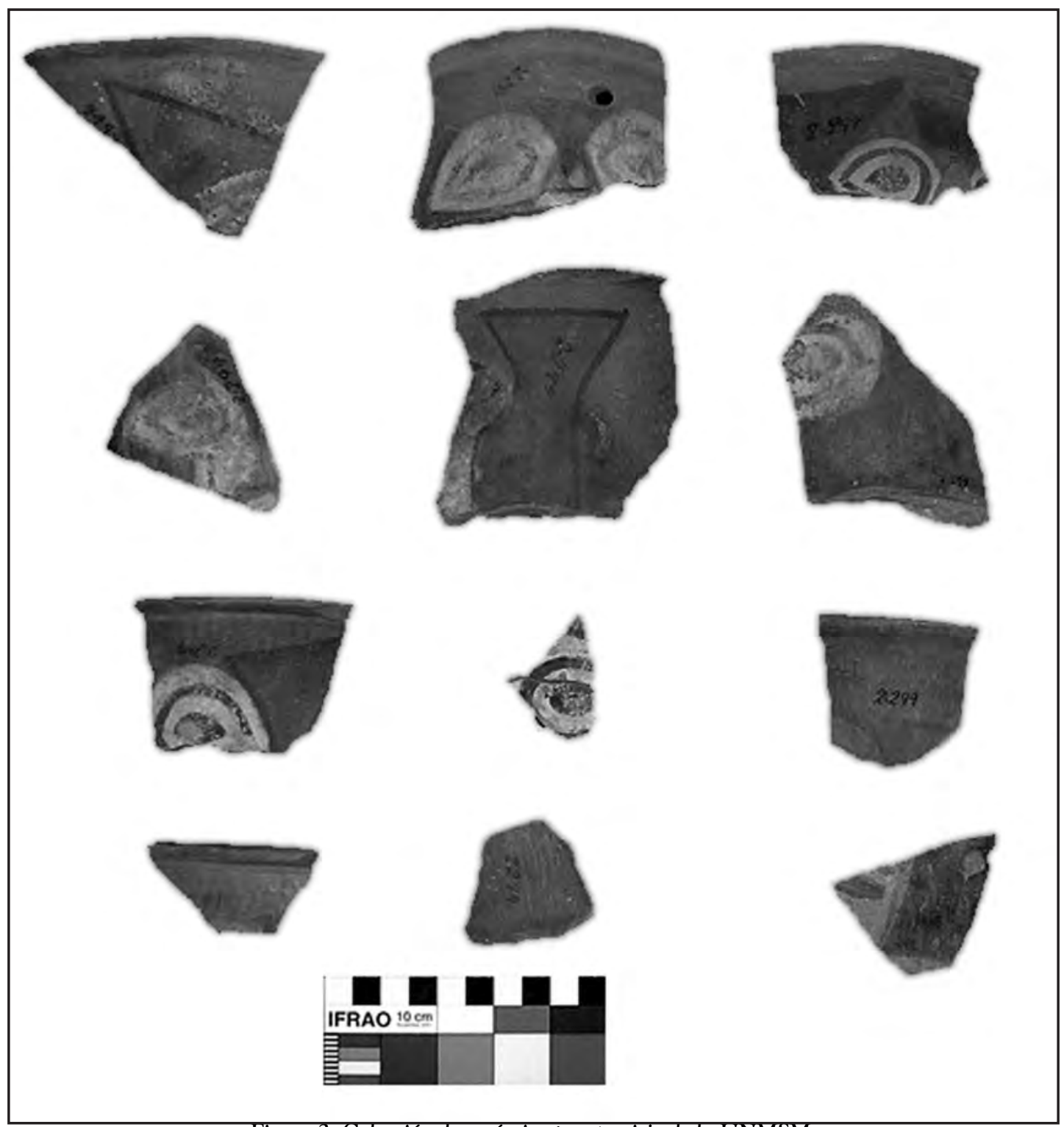

Figura 3. Colección de cerámica puerto viejo de la UNMSM.

también obedecería a cuestiones topográficas o de explotación de recursos naturales concretos. Sin embargo, planteábamos una relación económica entre ellas dentro de una red de intercambio de productos.

El valle de Mala, por lo menos para la parte baja y media, tuvo como organización social pre-existente inmediatamente a la ocupación
Inca, es decir, contemporánea a la denominada Ychma, a una sociedad de tipo comunitaria cuyas principales actividades productivas fueron la pesca y la agricultura y que no expresó materialmente, tanto en sus asentamientos como en su materialidad social, especialmente, en la producción, distribución y consumo de cerámica, una organización socio-económica y 


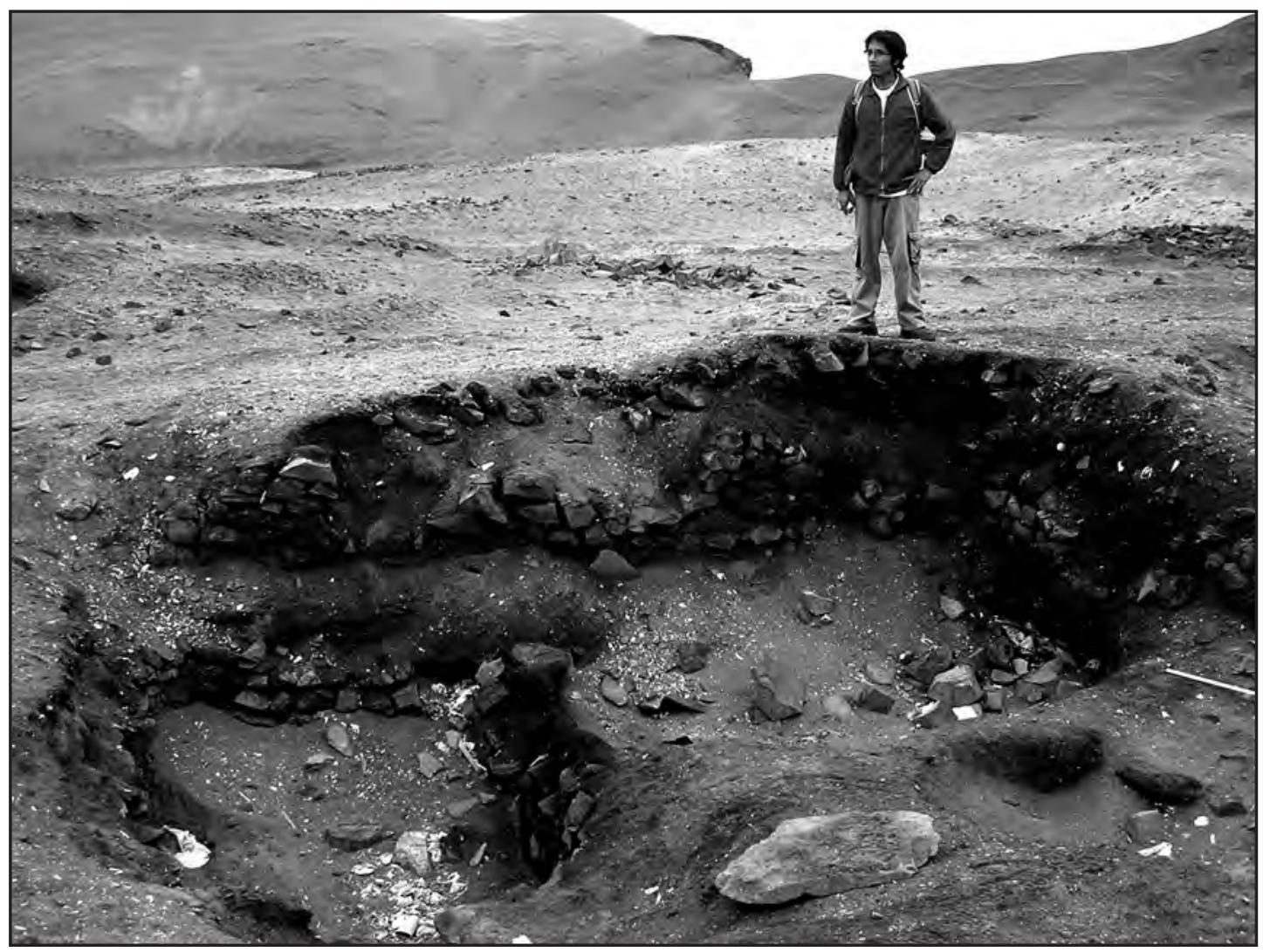

Figura 4. Sitio arqueológico de la ensenada.

sociopolítica asimétrica. De hecho, los asentamientos de la sociedad local solo se reconocen como pequeñas aldeas que no sobrepasan las 50 unidades domésticas y no se caracterizan por la monumentalidad arquitectónica o espacios excluyentes sino, más bien, por acumulaciones sin ordenamiento marcado de espacios domésticos básicos y "abiertos" que representarían un modo de vida comunitario. Un buen ejemplo de estos asentamientos, lamentablemente bastante disturbado y, últimamente privatizado, es el de La Ensenada, cercano al litoral.

Adentro del valle mismo, este grupo social mantiene los mismos elementos característicos ya observados por nosotros en el área cercana al litoral. Es decir, se tratan de asentamientos nucleados aun cuando contaban con espacio más amplios para la construcción de sus asentamientos, como las zonas llanas de la desembocadura del rio y el litoral. Valle adentro, los asentamientos son construidos en los conos aluviales en la base de cerros, lugares donde no se realizaban actividades agrícolas. Las unidades domésticas están caracterizadas por ser semi-subterráneas, de planta cuadrangular o rectangular y porque cada una de ellas manejaba sus propios depósitos y donde no se han reportado complejos de depósitos alejados y disociados de las unidades domesticas. La técnica de construcción estaba constituida por paredes compuestas por piedras de campo semi-canteadas unidas con argamasa de barro. Los recintos poseían esquinas curvas, una característica significativa en dicho tipo de arquitectura. 
La gran cantidad de cerámica de la tradición Puerto Viejo ${ }^{6}$, principalmente de los famosos cantaros cara-gollete, hallada en estos asentamientos nuevamente revelaba la gran producción de esta y que se realizaría en la mayoría de los asentamientos. Muchas veces se halla cerámica deformada o rota por su control deficiente en los hornos de producción. Por el material de superficie observado en estos asentamientos se puede afirmar que la alimentación se basaba en los recursos marinos, aunque la dieta también incluía vegetales como la calabaza (Fig. 5). Asimismo, sectores casi siempre alejados del núcleo doméstico, conformados por espacios superficialmente limpios de plantas rectangulares delimitados por piedras, servirían para el secado de pescado u otros productos marinos?

Un posible segundo grupo social se comienza a observar valle arriba, a la altura de la $\mathrm{Ha}$ cienda Tutumo (donde Manuel Gonzales Prada

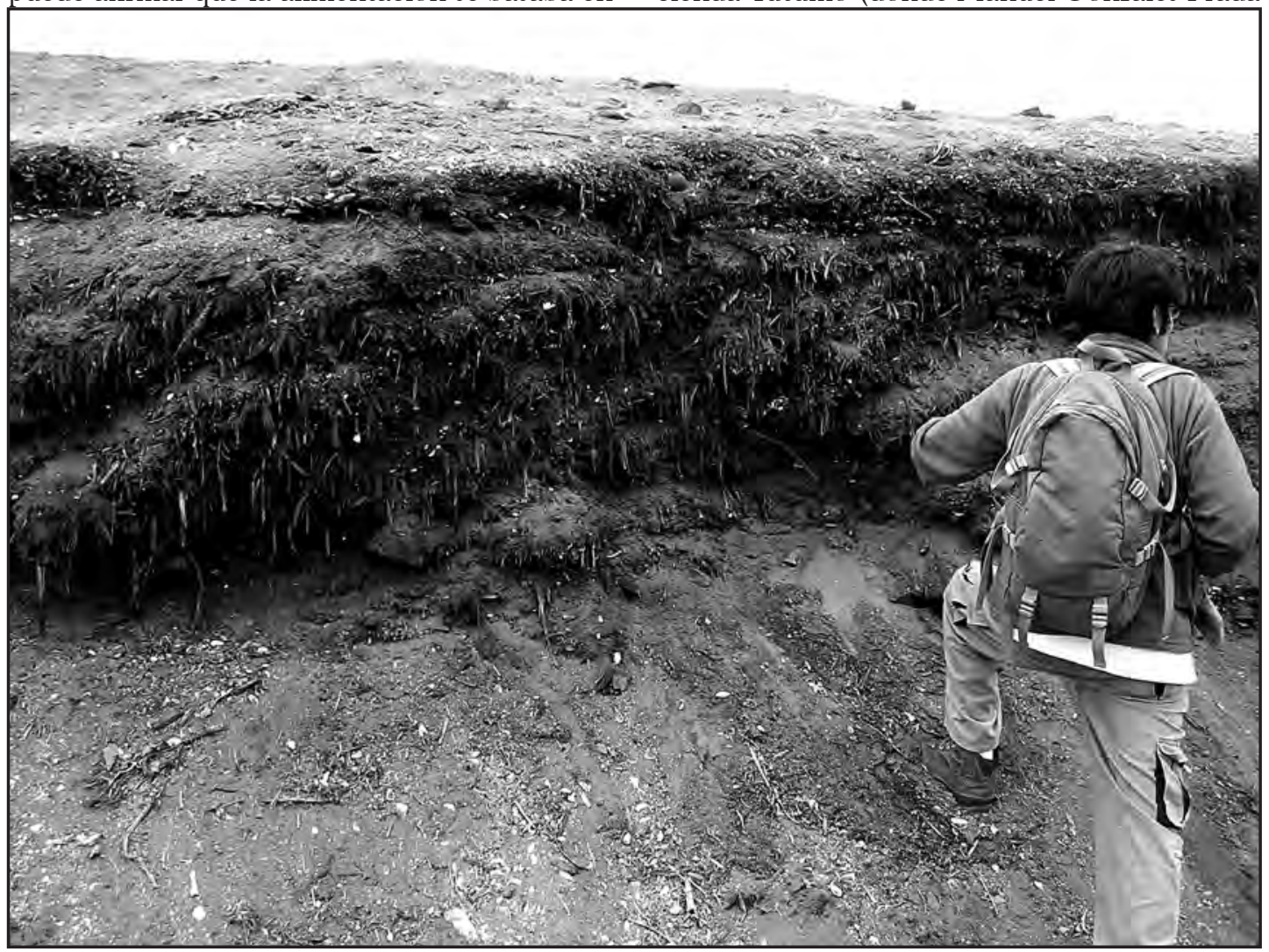

Figura 5. Vista de denso basural en el sitio de La Ensenada.

6 Preferimos utilizar el termino Tradición al de Estilo porque el primero se refiere a una forma de hacer las cosas en las cuales su producción predomina con relación a sus características externas o decorativas evadiendo la suposición de que cosas que se parecen (formalmente) son contemporáneas o proceden de un mismo lugar. Sin embargo, existe un problema con el estilo Puerto Viejo pues este es ampliamente conocido en la literatura arqueológica. En el futuro, según avancen las investigaciones, será necesario realizar algunos cambios en la forma de definir a las tradiciones cerámicas de los valles de Chilca, Mala y Asia.

7 Estructuras similares a las que encuentra Mujica et al. 1992 en el sitio Malanche 16 de la quebrada del mismo nombre al norte de la quebrada de Chilca. Aunque para ellos dichas estructuras servirían para prácticas relacionadas con tratamientos post-mortem de individuos de los mismos asentamientos. 
tuvo una casa hacienda), en asentamientos domésticos con recintos habitacionales de planta rectangulares construidos en las pendientes de los cerros mediante aterrazamientos artificiales o cercanos a la base de los cerros de una extensión entre 1 a 3 hectáreas. El material de construcción empleado es la piedra de cerro unida con argamasa de barro y revestida con barro. La construcción casi forzada de estos asentamientos en esta parte del valle estaría condicionada por la poca disponibilidad de suelos agrícolas y por el mismo encañonamiento del valle. Una característica especial de estos asentamientos en contraposición a los de valle bajo-litoral, es la presencia de enterramientos dentro de algunas estructuras domésticas y en algunos casos de tipo chullpario.

Asimismo, se distingue de los asentamientos de valle bajo-litoral por una cerámica doméstica de apariencia tosca y sin decoración pintada producida en atmósfera reductora que le confiere ese color marrón y negro, en la que sobresale como forma de decoración las impresiones circulares realizadas cuando la superficie de la vasija estuvo blanda. Todas las formas cerámicas apreciadas en estos asentamientos son pertenecientes al ámbito doméstico, es decir, estamos ante ollas y cántaros. Este tipo de ce-

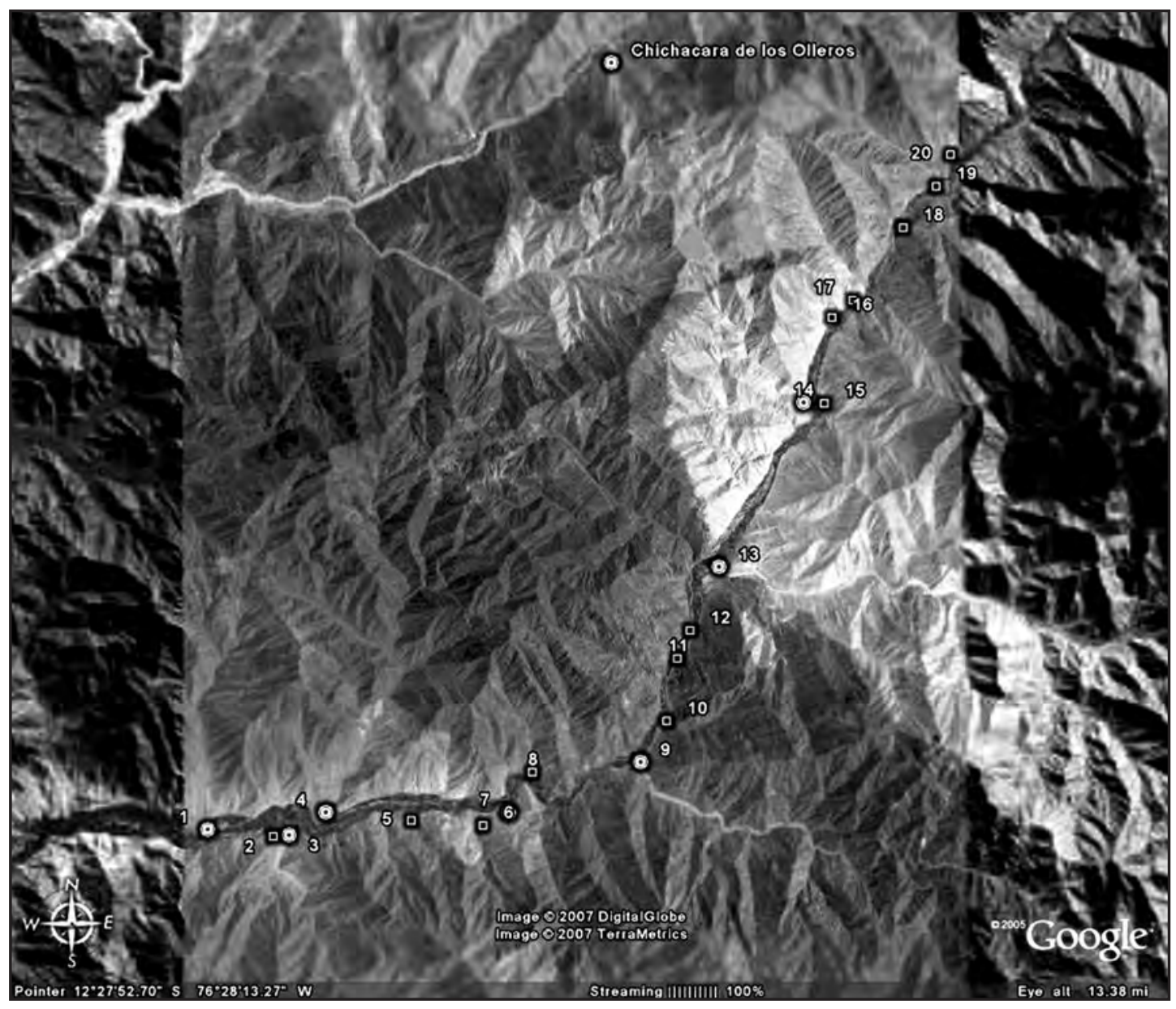

Figura 6. Vista satelital con los principales sitios inca del valle medio de mala. 
rámica es semejante a la de los valles medio y alto de otros lugares de la costa central. Sin embargo, la cantidad de fragmentos cerámicos hallados en estos sitios, es notablemente inferior con relación a los sitios asociados con la cerámica Puerto Viejo.

\subsection{La ocupación inca del} valle de mala

Como consecuencia de esta realidad social local, los invasores Inca habrían desplegado una estrategia de dominación directa o territorial (D'Altroy 1992) construyendo infraestructura para el dominio y control de la producción local y la fuerza de trabajo, materializado en los "Centros Administrativos", localizados algunos en áreas no productivas previamente $\mathrm{y}$ caminos que los conectaban, una estrategia reconocida en situaciones históricas similares en la costa peruana ${ }^{8}$.

Nuestras investigaciones plantean que, por su propia naturaleza, este valle en tiempos prehispánicos se habría utilizado, principalmente, como un camino natural que une la sierra (Huarochiri y Yauyos) con la costa central. Asimismo, del valle de Mala parten o llegan caminos transversales que lo unen por el norte con la Quebrada de Chilca (Engel 1987) y

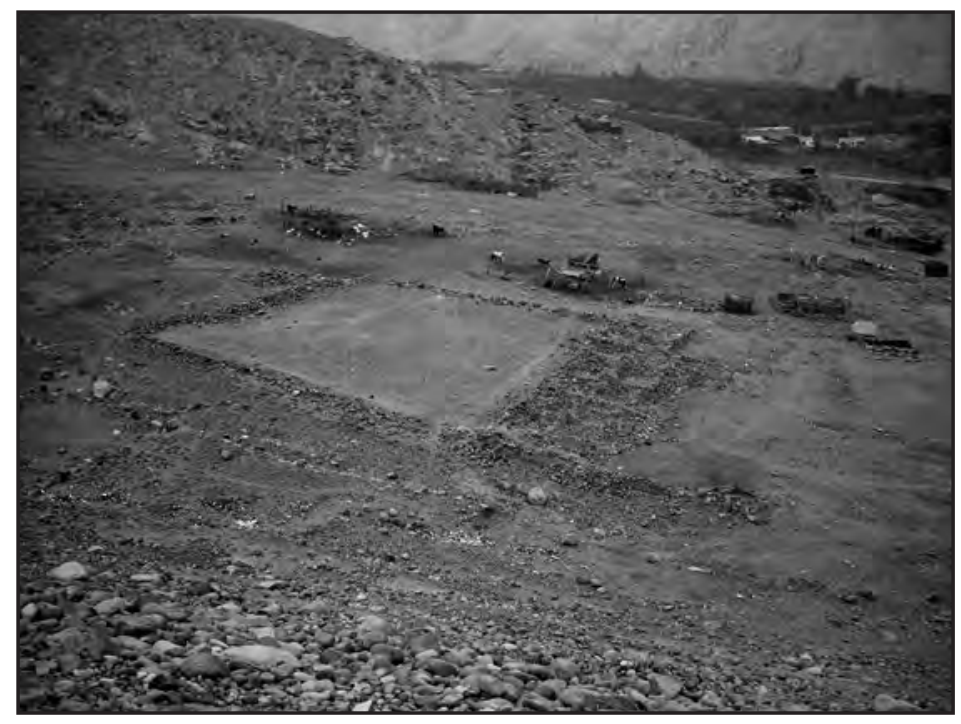

Figura 7. El complejo de colcas del sitio inca de La Vuelta.

por el sur con el valle de Omas (Coello 1993, Baca 2004), conectando diferentes espacios de explotación de recursos naturales o fuerza de trabajo. Sin embargo, estos caminos son esencialmente rutas naturales y no caminos formalizados.

Dicha articulación de espacios se hace patente en la época Inca cuando grandes asentamientos y caminos conectan dichas rutas. De hecho, algunos de estos sitios, que se pueden calificar como Centros Administrativos Inca (Hyslop 1990), se hallan en la encrucijada de caminos principales con infraestructura como sistemas de almacenaje o colcas, corrales, etcétera, que acusan la acumulación de productos y recursos naturales. Además de estos dos elementos: asen- tamientos y caminos, existen conjuntos de petroglifos, que se hallan complementando dicho espacio de movimientos sociales (Tantaléan y Pinedo en prensa).

\section{Comentarios Finales}

De las cuestiones anteriormente discutidas y de la materialidad social presentada en este artículo se pueden desprender varios planteamientos que necesitaran ser corroborados y ampliados por otr@ s investigador@s en el futuro inmediato, si se quiere avanzar en el conocimiento de las sociedades de la costa central que aparecen inmediatamente después de los fenómenos socioeconómicos y sociopolíticos del denominado Horizonte Medio y centralizados en los

8 Para una síntesis de las estrategias Inca de dominación, ver Stanish 2001. 


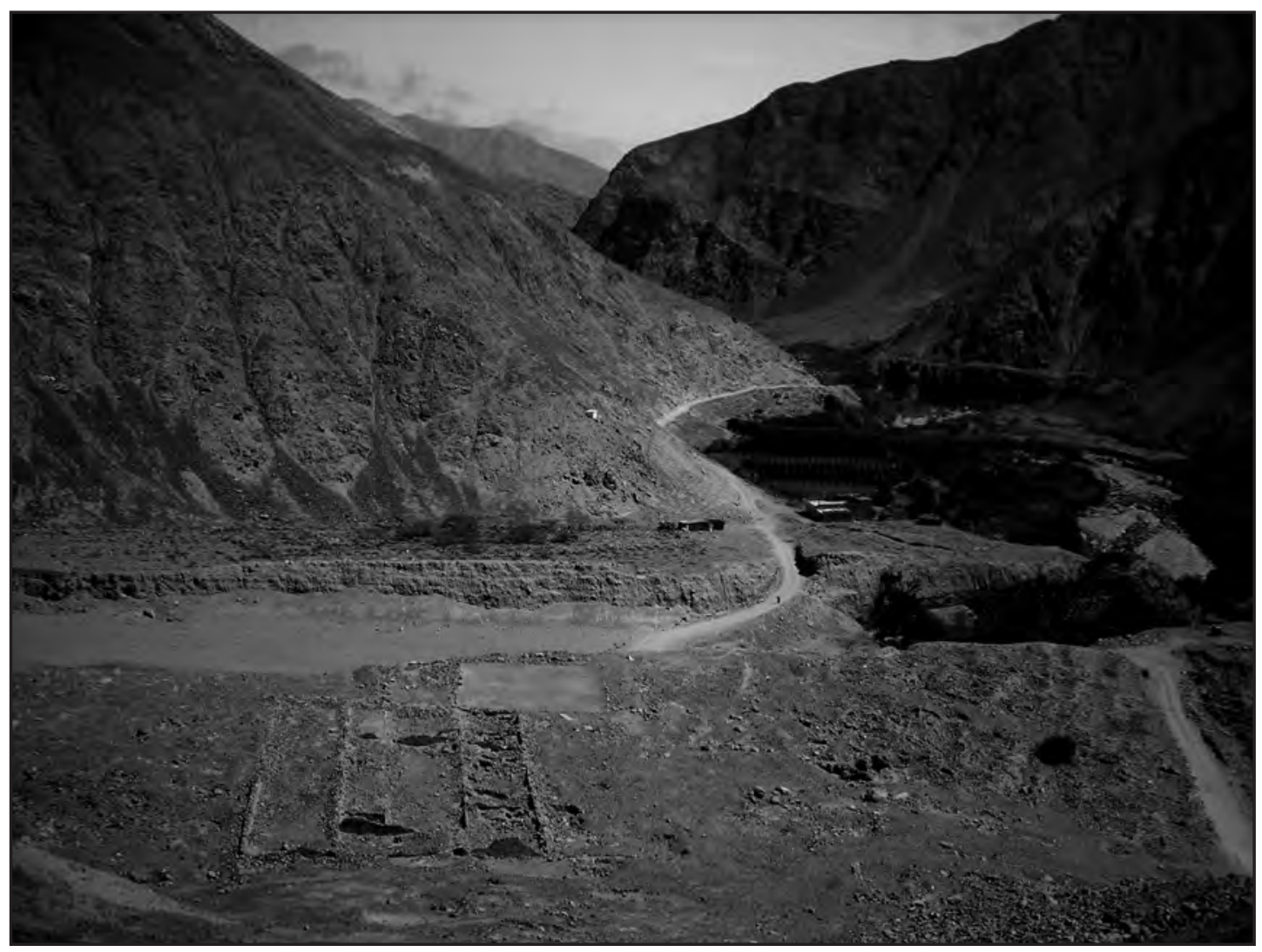

Figura 8. Vista desde el este del edificio principal de cochahuasi.

valles de Lurín (Pachacamac) y del Rímac (Cajamarquilla y Nieveria).

Lo primero que se puede avanzar es que la comprensión de las sociedades de la costa central se ha visto impedida de crecer por sus propias categorías que a modo de "corset idealista" han constreñido a la realidad social prehispánica sin darle espacio para su "revelación" a $1 @ s$ arqueólog@s (Tantaleán 2005).

En segundo lugar y con relación a la metodología, la anterior concepción de las sociedades y su supuesta corroboración empírica ha homologado la existencia de cerámica o arquitectura con la existencia de sus productor@s en el área donde estas se han hallado. Debemos comprender que las tipologías se deben realizar atendiendo a los contextos arqueológicos donde los artefactos planteen una producción local.
Por ejemplo, para el caso de las PCR's, la tipología de estos edificios ha servido como una importante heurística acerca de la extensión de una forma de producir edificios monumentales pero no debe ser asumida tan a apriorísticamente. Asimismo, con respecto a la cerámica y para el caso tardío de lo Ychma, las tumbas aportan un ingente material para el análisis de las relaciones sociales pero, por eso mismo, son consecuencia de complicadas prácticas sociales, donde las practicas socio-políticas son relevantes para entender el porqué ciertos artefactos llegan a las tumbas de determinados sujetos. Como ya apuntaba Tom Dillehay (2003), la producción local a veces suministra de materiales como la cerámica para realizar funciones generalmente asignadas a la cerámica Inca Imperial. El caso de la costa central es significativo aquí. 
Por ello, desde la época de las excavaciones en Pachacamac de Max Uhle (1903) y Gordon Willey, William Strong y John Corbett (Strong y Corbett 1943), las vasijas conocidas como Inca Asociado deben tomarse como la supervivencia (e incluso, incremento) de la producción local, como sería el caso de la cerámica Puerto Viejo, y está en nosotr@s reconocer de donde proceden esos artefactos y no solo constatar su existencia.

En tercer lugar, y relacionado con el anterior punto, las investigaciones en los valles bajos de Chilca (Ojeda 1976, Engel 1984, 1987), Mala (Gabe 2000) y Asia (Ángeles y Pozzi-Es$\cot 2004$, Baca 2004) vienen demostrando que en el período Intermedio Tardío existía en esta área una tradición local que tenía características socioeconómicas y sociopolíticas propias. ${ }^{9}$

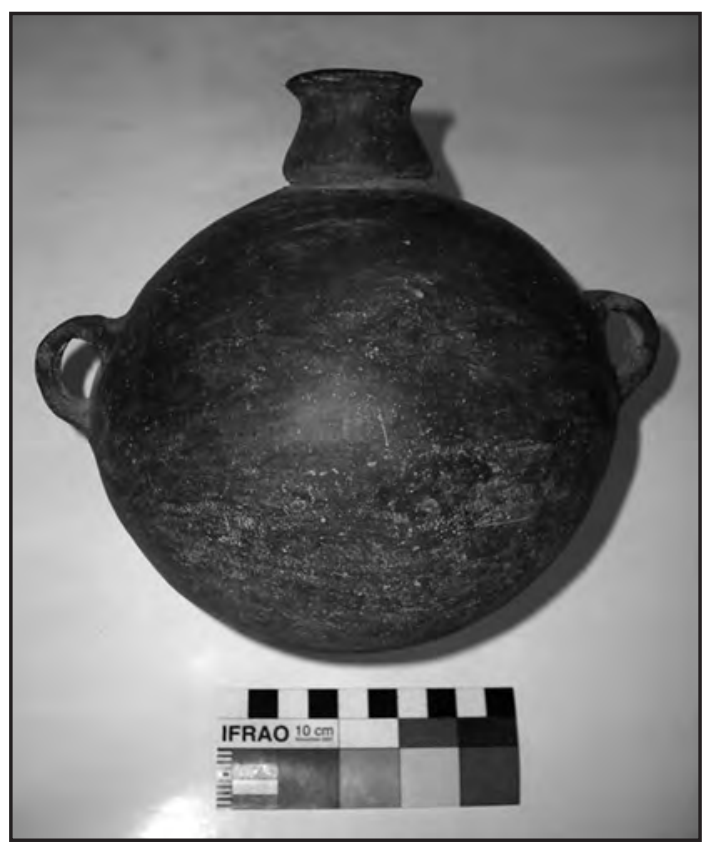

Figura 9. Cerámica alloca hallada en el sitio arqueologico de Huancani.
De hecho, si se quiere, se puede avanzar que esa cerámica conocida como Puerto Viejo no debería incluirse dentro de la tradición cerámica Ychma (como se plantea en Vallejo 2004) sino que más bien pertenece a una producción local en asentamientos domésticos con características similares que arrancaría en el Horizonte Medio 3, como ya sugerían Frederic Engel (1984, 1987 incluso con fechados) y Duccio Bonavia décadas atrás y se extendería durante la época Inca como se da en el caso en la mayoría de los centros administrativos inca del valle de Mala. Incluso recientemente, una nueva tradición local viene siendo encontrado asociado con los asentamientos propiamente Inca de valle medio lo que complica más aún la escena local de este periodo.

Para finalizar, solo nos queda decir que más investigaciones son necesarias en la costa central pero, sobre todo, debemos intentar hacer una auto-crítica de los razonamientos que nos llevan a presentarlas a nuestro principal consumidor: la sociedad. Después de todo, es a esta a la que nos debemos y retornarle la vida a nuestras sociedades en estudio, supone que nosotros seamos el puente entre los vivos y los muertos en esa laguna Estigia que es el pasado pero que, como observaban el poeta florentino, esta cubierto por vapores que no dejan ver claramente lo que sucede en la otra orilla. Por ello, en esa responsabilidad de dar una imagen cada vez más clara del pasado,1@s arqueólog@s deberemos estar dispuestos a entregar razonamientos que iluminen nuestro camino y no lo oscurezcan.

\section{Agradecimientos}

L@s chic@s de la base 2003 de arqueología de la UNMSM siempre fueron un gran aliciente para darle forma y fondo a las ideas que conforman texto. Cuando me hallaba en Barce-

9 Asimismo, resulta significativo que en la descripción de los reconocimientos de los asentamientos arqueológicos en las quebradas y lomas entre Lurín y Chilca, Elías Mujica (Mujica et al. 1992) no mencione la aparición de cerámica relacionada con el estilo Puerto Viejo. 
lona dictando clases pudieron hacer realidad el simposio que ahora se publica. A pesar que no estuve presente con ell@s en esos momentos de discusión de ideas siempre me sentí y me hicieron formar parte de ese proceso. Les agradezco infinitamente por haberme convertido en su profesor y dejarme ser su amigo.

\section{Bibliografía}

Ángeles, Rommel y Denise Pozzi-Escot

2004 Del Horizonte Medio al Horizonte Tardio en la Costa Sur Central: el Caso del Valle de Asia. Bulletin del'Institut Français d'Etudes Andines, 3(3):861-886.

Baca, Emily

2004 Excavaciones en el sitio de Uquira, Valle de Asia. Boletín de Arqueología PUCP, 8. Lima.

Bazán Del Campo, Francisco

1990 Arqueología y Etnohistoria de los Períodos Prehispánicos Tardíos de la Costa Central del Perú. Tesis de Licenciatura. Universidad Nacional Mayor de San Marcos. Lima.

Bonavia, Duccio

1959 Cerámica de Puerto Viejo (Chilca). Actas del II Congreso Nacional de Historia del Perú (Época Prehispánica): 137-168. Centro de Estudios Históricos y Militares del Perú. Lima.

1965 Arqueología de Lurín (Seis Sitios de Ocupación en la Parte Inferior del Valle). Instituto de Estudios Etnológicos del Museo Nacional de la Cultura Peruana y el Departamento de Antropología de la Universidad Nacional Mayor de San Marcos. Lima.

Bobbio, Norberto

1987 La Teoría de las Formas de Gobierno en la Historia del Pensamiento Político. Fondo de Cultura Económica. México.
Brumfiel, Elizabeth y John Fox

1994 Factional Competition and Political Development in the New World. Cambridge University Press. Cambridge.

Bueno Alberto

1982 El Antiguo Valle de Pachacamac. Espacio, Tiempo y Cultura. Boletín de Lima, 25. Lima.

Cock, Guillermo

2005 Inca Rescue. National Geographic. Disponible en: http://magma.nationalgeographic.com/ngm/0205/feature5/index.html

Coello, Antonio

1993 Los Coayllo: Una Ocupación Durante el Intermedio Tardío. Una Visión Etnohistórica. Sequilao, Año II, Nro 2. Lima.

Cornejo, Miguel

2000 La Nación Ischma y la Provincia Inka de Pachacámac. Arqueológicas, 24: 147-172. Lima.

2002 Sacerdotes y Tejedores en la Provincia Inka de Pachacamac. Boletín de Arqueología PUCP, 6: 171-204. Lima.

D'Altroy, Terence

1992 Provincial Power in the Inka Empire. Smithsonian Instituion Press. Washington D. C.

2003 Los Incas. Ariel. Barcelona.

Díaz, Luisa

2004 Armatambo y la Sociedad Ychsma. Bulletin del 'Institut Français d'Etudes Andines, 3(3):571-594.

Díaz, Luisa y Francisco Vallejo

2002 Identificación de Contextos Ichma en Armatambo. Arqueología y Sociedad, 14: 47-76.

Dillehay, Tom

2003 El Colonialismo Inka, el Consumo de Chicha y los Festines Desde una Perspectiva de Banquetes Políticos. Bole- 
tín de Arqueología PUCP, 7: 355-363. Lima.

Earle, Timothy

1978 Economic and Social Organization of a Complex Chiefdom: The Halalea District, Kanai, Hawaii. Anthropological Paper 63. Museum of Anthropology. University of Michigan. Ann Arbor.

Eeckhout, Peter

1997 Pachacamac (Côte Centrale du Pérou). Aspects du Fonctionnement, du Développement et de l'Influence du Site Durant l’Intermédiaire Récent (ca 900-1470). Tesis Doctoral. Universidad de Bruselas.

1999 Pachacamac Durant l'Intermediaire Récent. Étude d'un Site Monumental Prehispanique de la Côte Centrale du Pérou. British Archaeological Reports, International Series, 747.

2003 Ancient Monuments and Patterns of Power at Pachacamac, Central Coast of Peru. Beiträge zur Allgemeinen und Vergleichenden Archäologie, 23: 139. 182.

2004 La Sombra de Ychsma. Ensayo Introductorio Sobre la Arqueología de la Costa Central del Perú en los Periodos Tardíos. Bulletin del'Institut Français D’Etudes Andines, 33 (3): 403-423.

Engel, Frederic

1966 Geografía Humana Prehistórica y Agricultura Precolombina de la Quebrada de Chilca. Universidad Nacional Agraria de la Molina. Lima.

1984 Prehistoric Andean Ecology: Man, Settlement and Environment in the Andes. Chilca. Hunter College of the City. Department of Anthropology. University of New York. New York.

1987 De las Begonías al Maíz: Vida y Producción en el Perú Antiguo. Centro de
Investigaciones de Zonas Áridas. Universidad Nacional Agraria La Molina, Lima.

Estete, Miguel de

1947[1534] La Relación del Viaje que hizo el Señor Capitán Hernando Pizarro por mandato del Señor Gobernador su Hermano, desde el Pueblo de Caxamalca á Parcama, y allí a Jauja. Biblioteca de Autores Españoles, Tomo XXVI. Ediciones Atlas. Madrid.

Farfán, Carlos

2004 Aspectos Simbólicos de las Pirámides con Rampa. Ensayo Interpretativo. Bulletin de l'Institut Francais d'Études Andines, 33(3): 449-464. Lima.

Feltham, Jane

1983 The Lurin Valley, Peru: AD 1000. 1532. Tesis Doctoral. Universiy College of London. London.

Feltham, Jane y Peter Eeckhout

2004 Hacia una Definición del Estilo Ychma: Aportes Preliminares sobre la Cerámica Ychsma Tardía de la Pirámide III de Pachacamac. Bulletin del 'Institut Français d'Etudes Andines, 3(3):643680.

Gabe, Carmen

2000 Investigaciones Arqueológicas en el Cerro Salazar-Mala. Centro de Estudios Arqueológicos y Medio Ambiente. Serie Investigaciones Arqueológicas, 1. Lima.

Gil García, Francisco

2001 De 'Tumbas Reales' a 'Chullpas-enel-Paisaje' Pasando por los 'Ayllus de Sepulcros Abiertos'. Reflexiones Epistemológicas sobre casi dos Siglos de Arqueología del Fenómeno Chullpario. Arqueoweb, 3(3): http://www. ucm.es/info/arqueoweb . Diciembre.

2002 Acontecimientos y Regularidades 
Chullparias: Más Allá de las Tipologías. Reflexiones en Torno a la Construcción del Paisaje Chullpario. Revista Española de Antropología Americana, 32: 207-241. Madrid.

Hernando, Almudena

2002 Arqueología de la Identidad. Akal. Madrid.

Hobsbawn, Eric

1992 Naciones y Nacionalismo desde 1780. Crítica. Barcelona.

Hodder, Ian

1988 Interpretación en Arqueología. Corrientes Actuales. Crítica. Barcelona.

1995 Theory and Practice in Archaeology. Routledge. London.

2000 Towards Reflexive Method in Archaeology: The Example at Çatalhöyük. McDonald Institute for Archaeological Research / British Institute of Archaeology at Ankara Monograph No. 28. Cambridge.

Hyslop, John

1990 Inka Settlement Planning. University of Texas Press. Austin.

Iriarte, Francisco

1960 Algunas Apreciaciones sobre los Huanchos. En R. Matos (comp.): Antiguo Perú: Espacio y Tiempo: 259-263. Mejía Baca. Lima.

Johnson, Allen y Timothy Earle

2003 La Evolución de las Sociedades Humanas. Ariel Prehistoria. Barcelona.

Makowski, Kzsiztoff y Milena Vega-Centeno

2004 Estilos Regionales en la Costa Central en el Horizonte Tardío. Una Aproximación desde el Valle de Lurin. Bulletin de l'Institut Francais d'Études Andines, 33(3): 681-714. Lima.

Marcone, Giancarlo

2004 Cieneguilla a la Llegada de los Incas. Aproximaciones desde la Historia
Ecológica y la Arqueológica. Bulletin de l'Institut Francais d'Études Andines, 33(3): 715-734. Lima.

Michczynski, Adam, Peter Eeckhout Y Anna Pazdur

2003 Absolute Chronology of the Pyramid III and the Dynastic Model at Pachacamac, Peru. Radiocarbon, 45:1-12.

Milla, Carlos

1974 Catastro de los Valles del Rímac y Santa Eulalia. INC. Lima.

Moore, Jerry

1996a Architecture and Power in the Ancient Andes. The Archaeology of Public Buildings. Cambridge University Press. Cambridge.

1996b The Archaeology of Plazas and the Proxemics of Ritual. Three Andeans Traditions. American Anthropologist, 98(4): 789-802.

2005 Cultural Landscapes in the Ancient Andes. Archaeologies of Place. University Press of Florida. Gainesville.

Moseley, Michael

1975 Chan Chan: Andean Alternative of the Preindustrial City. Science, 187 (4173): 219-225.

Mujica, Elías, José Pablo Baraybar y Aldo Bolaños

1992 Malanche 22: Prácticas Mortuorias Complejas y Modo de Vida en una Aldea de Lomas Tardía de la Costa Central del Perú. Gaceta Arqueológica Andina, 21: 81-107.

Negro, Sandra

1977 Patrones de Asentamiento Pre-Hispánico en el Valle de Turín. Tesis de Licenciatura. Universidad Ricardo Palma. Lima.

Ojeda, Bernardino

1976 Trabajos de campo en Chilca y Mala para el CIZA. Manuscrito inédito. 
Paredes, Ponciano y Régulo Franco

1987 Pachacamac: Las Pirámides con Rampa, Cronología y Función. Gaceta Arqueológica Andina, 13: 5-7.

PIZARRO, Hernando

1968 [1533] Carta de Hernando Pizarro "A los Magníficos Señores Oidores de la Audiencia Real de su Majestad que Residen en la Ciudad de Santo Domingo". Biblioteca Peruana, Primera Serie, Volumen I: 117-130. Editorial Técnicos Asociados S.A. Lima.

POLANYI, Karl

1957 The Economy as Instituted Process. En Polanyi, Karl, C. Arensberg y H. Pearson (eds): Trade and Market in the Early Empires: 243-270. Free Press. New York.

RAVINES, Rogger

1996 Pachacamac. Santuario Universal. Los Pinos. Lima

ROSTWOROWSKI, Maria

1972 Breve Ensayo sobre el Señorío de Ychma o Ychima. Revista Arqueología PUC: Boletín del Seminario de Arqueología, 13. PUCP. Lima.

SÁNCHEZ, Ángel

2000 Relaciones Sociales Serrano Costeñas durante el Intermedio Tardío en el Valle del rio Lurín. Arqueológicas, 24:129-147.

SERVICE, Elman

[1975]1984 Los Orígenes del Estado y de la Civilización. Alianza. Madrid.

SHIMADA, Izumi

1991 Pachacamac Archaeology. Retrospect and Prospect. En Pachacamac. A Reprint of the 1903 edition by Max Uhle. University Museum Monograph 62. The University Museum of Archaeology and Anthropology. University of Pennsylvannia. Philadelphia.
SILVA, Jorge y Cecilia JAIME

2005 Etnoarqueología del Bajo Rímac y el Callao Prehispánico. Investigaciones Sociales, 15:29-42. Lima.

STANISH, Charles

2001 Recent Regional Research on the Inca. Journal of Archaeological Research, 9(3): 213-241.

STRONG, William y John CORBETT

1943 A Ceramic Sequence at Pachacamac. En Strong, William, Gordon Willey y John Corbett: Archaeological Studies in Peru, 1941-1942: 27-122. Columbia Studies in Archaeology and Ethnology 1(3). New York.

TANTALEÁN, Henry

1995 El Intermedio Tardío en la Desembocadura del Rio Mala. En Echevarria, Gori (ed.): El VI Congreso Nacional de Estudiantes de Arqueologia y la UNMSM: 65-73. Lima.

2005 Arqueología de la Formación del Estado. El Caso de la Cuenca Norte del Titicaca. Avqi Ediciones. Lima.

En prensa Las Fronteras Elusivas: Territorios Discontinuos y Sociedades Tardías Prehispánicas de la Costa Centro-Sur del Perú. En Tantaleán, H. y O. Pinedo (eds): Al Sur de Pachacamac: Arqueología de Chilca, Mala y Asia. Avqi Ediciones. Lima.

TANTALÉAN, Henry y Omar PINEDO

2005 Acerca de la Ocupación Inca en el Valle de Mala (Cañete). Arqueología y Sociedad, 15: 135-154. Lima.

2007 Construyendo un Horizonte: La Arquitectura Inca del Valle de Mala (Cañete, Lima). Arkinka, 137: 86-93.

En prensa Las Piedras en el Camino: Petroglifos y Desplazamientos Sociales Durante la Época Inca en el Valle de Mala, Costa Central Del Perú. En Actas del 
TELLO, Julio

VII Simposio Internacional de Arte Rupestre. Arica.

1959 Paracas. Primera Parte. UNMSM. Lima.

Thomas Julian

1996 Time, Culture and Identity. An Interpretive Archaeology. Routledge. London.

Tilley, Christopher

1994 A Phenomenology of Landscape. Places, Paths and Monuments. Berg. Oxford.

2004 The Materiality of Stone. Explorations in Landscape Phenomenology. Berg. Oxford.

Uhle, Max

(1903)1991 Pachacamac. A Reprint of the 1903 edition by Max Uhle. University Museum Monograph 62. The University Museum of Archaeology and Anthropology. University of Pennsylvannia. Philadelphia.

Vallejo, Francisco

2004 El Estilo Ychsma: Características Generales, Secuencia y Distribución Geográfica. Bulletin del'Institut Français d'Etudes Andines, 3(3): 595 642.

Villacorta, Luis Felipe

2003 Palacios y Ushnus. Curacas del Rímac y Gobierno Inca en la Costa Central. Boletín de Arqueología PUCP, 7. Lima.
2004 Los Palacios en la Costa Central Durante los Períodos Tardíos: De Pachacamac al Inca. Bulletin de l'Institut Francais d'Études Andines, 33(3): 539-570. Lima.

Villar Córdova, Pedro

1935 Las Culturas Pre-Hispánicas del Departamento de Lima. Municipalidad de Lima.

Vogel, Melissa

2003 Life on the Frontier: Identity and Sociopolitical Change at the Site of Cerro la Cruz, Peru. Tesis doctoral. Departamento de Antropología, Universidad de Pennsylvania, Philadelphia.

Williams, Carlos y Francisco Merino

1976 Inventario, Catastro y Delimitación del Patrimonio Arqueológico del Valle de Mala. Instituto Nacional de Cultura. Lima.

Yofee, Norman

2005 Myths of the Archaic State. Evolution of the Earliest Cities, States, and Civilizations. Cambridge University Press. Cambridge. 